\title{
O Museu Vivo Antonio Samias e a sustentabilidade sociocultural dos índios Kokama
}

\author{
Daniela Sulamita Almeida da Trindade* \\ Denis Gomes Cordeiro**
}

Trindade, D.S.A.; Cordeiro, D.G. O Museu Vivo Antonio Samias e a sustentabilidade sociocultural dos indios Kokama. R. Museu Arq. Etn., 30 104-117, 2018.

Resumo: A criação da Associação dos Índios Kokamas Residentes no Município de Manaus (AKIM) tem ampliado as possibilidades de fortalecimento da identidade e alcance de políticas públicas definidas para os povos indígenas, submetidos a um processo de invisibilidade social desde a ocupação da Amazônia pelos colonizadores. Esta pesquisa qualitativa, de caráter bibliográfico, tem como objetivo analisar a articulação comunitária dos Kokama na criação do Museu Vivo Antônio Samias como forma de reafirmação da identidade étnica e sustentabilidade sociocultural. Desse modo, percebeu-se que, ao agirem em comunidade/organização sociopolítica, na luta pelo processo de ressignificação cultural, os Kokama estabeleceram uma parceria com o Projeto da Nova Cartografia Social da Amazônia (PNCSA) para reforçar as práticas sociais de seu povo e de seus líderes, como mecanismo de fortalecimento da memória e resistência étnica.

Palavras-chave: Identidade indígena; Sustentabilidade sociocultural; Museu Vivo Antônio Samias; Ecomuseus; Diversidade cultural.

\section{Introdução}

- sta pesquisa visa, por meio de Euma análise sociológica, entender os mecanismos de lutas das comunidades tradicionais acerca da produção de sua visibilidade, da garantia de existência e de emancipação social mediante o processo de

\footnotetext{
*Mestra em Educação e Ensino de Ciências pela Universidade do Estado do Amazonas (UEA) e Doutoranda do Programa de Pós-Graduação em Sociedade e Cultura na Amazônia da Universidade Federal do Amazonas (Ufam). <danielasat76@gmail.com>

${ }^{* *}$ Graduado em pedagogia pela Universidade do Estado do Amazonas (UEA), pós-graduando em Neuropsicopedagogia Clínica e em Neuropsicopedagogia Institucional e Educação Especial Inclusiva do Censupeg. 〈denism12@gmail.com>
}

ocidentalização e ofuscamento da existência do diferente.

Aguiar (2012) contribui nesse sentido ao apontar o discurso narrativo como o instrumento de descrição, apresentação e caracterização dos sujeitos e grupos sociais na sociedade. Essa força de narrativa suscitada nas relações de poder atua, ressalta, inibe ou produz a inexistência do outro.

Assim, a produção e reprodução da ideia de "outro" - considerado estranho, selvagem e perigoso - é frequentemente incorporada à figura do indigena, do negro, do cigano, mas não dos brancos ocidentalizados, pois a narrativa sobre os diferentes foi produzida nos moldes da sociedade branca e cristã.

Diante desse cenário, tendo em vista os diferentes sistemas culturais que compõem o 
caleidoscópio da cultura brasileira, é preciso entender e situar a luta da etnia Kokama pela desconstrução do silenciamento que lhes foi imposto, ao mesmo tempo em que lutam para manter viva a sua língua e suas formas de conhecimento indígena, que não podem ser estabelecidas pela ciência ou pela filosofia.

Os museus vivos, aqui entendidos como um documento de identidade, emergem nesse terreno fértil para transformar processos sociais marginalizados em narrativas e iniciativas museais, que possibilitam a reflexão sobre a relação que esse povo estabelece com os recursos naturais, a fauna e principalmente com os rios, já que são considerados habitantes de territórios aquáticos (Rubin 2017).

Desde meados de 2012, no novo território, o povo Kokama amplia sua força política por meio da Associação dos Índios Kokamas Residentes no Município de Manaus (AKIM)² e busca tornar conhecida a sua história por meio da exposição de suas artes e de seus saberes no Museu Vivo Antonio Samias; "[...] local de rememorar e reconstruir a história, os mitos, os rituais, as vivências do cotidiano Kokama e de seus ikaros (músicas Kokama)" (Rubin 2017: 148).

Nesse cenário, a dimensão social e a dimensão cultural são aproximadas ao descortinar-se a luta dessa etnia pela garantia de seus direitos como cidadãos e ao organizarse o Museu Vivo como uma estratégia de reafirmação de sua identidade étnica. Torna-se, assim, necessária a reflexão sobre a sustentabilidade sociocultural e a manutenção de sua existência cultural no contexto urbano.

Essa investigação propõe analisar a articulação comunitária da étnia Kokama para a criação do Museu Vivo Antonio Samias, como mecanismo de reafirmação da identidade étnica e de garantia de existência sociocultural. A reafirmação da identidade por meio da

2 Até o ano 2012, residiam na comunidade Kokama Nova Esperança 15 famílias; famílias associadas eram 86 , sendo 15 residentes na comunidade e 71 fora dela. Nesse mesmo ano, a comunidade passou a ocupar uma propriedade $(55 \times 115 \mathrm{~m})$, no ramal do Brasileirinho, doada para a AKIM por Júlio Dias Batista (kokama), sua esposa Maria Lídia Dias de Sena Batista (kokama) e pela Suframa, em janeiro de 2012 (Almeida \& Rubin 2012). criação do Museu Vivo e a garantia de acesso a um conjunto de condições de vida são fatores que acenam para a efetivação da condição de existência sociocultural do povo Kokama na cidade de Manaus.

\section{Metodologia}

Esta pesquisa segue uma trajetória qualitativa e faz parte de um conjunto de atividades realizadas junto ao Programa de Pós-Graduação em Sociedade e Cultura na Amazônia, da Universidade Federal do Amazonas (Ufam). Caracteriza-se como descritiva, na medida em que permite identificar o dilema de fortalecimento da língua e cultura e a reivindicação pela garantia do direito à educação como motivações que impulsionaram o povo Kokama a criar o Museu Vivo Antonio Samias, na cidade de Manaus/ AM. Procurou-se descrever o fortalecimento político e coesão social dos Kokama, que,por meio da criação de sua associação comunitária e parceria estabelecida com a Universidade Federal do Amazonas, organizaram o museu como um espaço de materialização e fortalecimento da identidade cultural indígena. O caráter bibliográfico da pesquisa se deve aos estudos de teses, de livros e de periódicos que tratam dessa etnia.

\section{A comunidade Kokama Nova Esperança e a criação do Museu Vivo Antonio Samias}

Apontados nas descrições dos viajantes, cronistas naturalistas, historiadores e administradores coloniais durante séculos, os Kokama mantiveram relações conflituosas com outros povos na disputa por recursos hídricos e florestais. Devido ao seu constante deslocamento geográfico, "[...] os Kokama constituíam um povo $[\ldots]$ em constante [...] processo de deslocamento [...] atrelado a conflitos na busca de terras para plantio e de águas para o exercício da pesca" (Almeida \& Rubim 2012: 68).

Quanto à considerável expansão do povo Kokama, Silva (2012) afirma que os cronistas, 
exploradores e missionários, nos séculos XVI e XVII, apontaram a predominância cultural desse grupo linguístico de matriz Tupi em diferentes áreas da Amazônia, inclusive na Bacia do Alto Amazonas. Seus principais assentamentos localizavam-se no médio e baixo rio Ucayali, afluente do rio Amazonas peruano (Freitas 2002).

Segundo Aguiar (2012), os indígenas foram apresentados em termos genéricos. Aparecem nas narrativas do padre Acuña como homens fracos, inocentes, ingênuos e sujeitos à providência divina. Segundo o autor, na visão do padre jesuíta João Daniel, os indígenas tinham a natureza corrupta, eram ignorantes sobre Deus e lhes faltava leis. Uma clara demonstração de que para os jesuítas, as formas de religiosidade e representação de fé dos indígenas era algo intraduzivel.

Nas estratégias de contato dos missionários, por meio do Regimento das missões (1632), a promoção das mudanças nas formas de ser, de viver e de pensar consistiu em conhecer as línguas dos povos indígenas para dominá-los. Para governá-los, na visão do padre Daniel, ter prudência seria fundamental, pois, se o castigo os afugentava, o afago os fazia indolentes.

É nessa ocasião que as ações homogêneas e universalizantes da escola e das doutrinas religiosas funcionaram como estratégia para criar corpos que pudessem ser inseridos nas tarefas que exigiam o domínio do remo, a extração de produtos da natureza e a atuação no cultivo das lavouras, de acordo com as necessidades dos brancos colonos (Aguiar 2012).

A escola para ensinar meninos e meninas indígenas a língua portuguesa foi uma experiência realizada entre os anos de 1750 e 1760, no governo de Francisco Xavier de Mendonça Furtado, irmão do primeiro ministro marquês de Pombal. Além de proporcionar conhecimentos, a escola estimulou a produção de uma conduta, a descaracterização da cultura e fragilização da língua, com a prerrogativa de expropriar as terras indígenas e transformar os índios vencidos em aliados ou súditos inferiores.

A exigência preconizada pelo Diretório dos Índios, instituído pelo Marques de Pombal em agosto de 1758 , coibiu o sistema de alianças, reprimiu o uso do nheengatu, das línguas indígenas e demais práticas culturais, impondo a "língua do príncipe", o português. Essa medida consistia em inibir resistências e incentivar a obediência ao poder real (Almeida $\&$ Rubin 2012). A repressão tornou-se um instrumento decisivo para o funcionamento econômico do sistema agrário-exportador das monocultoras de algodão e cana-de-açúcar.

A identificação dos europeus em contraste com todos aqueles não europeus se manifesta na "ideia de identidade europeia como sendo superior em comparação com todos os povos e culturas não europeus" (Said 1990: 19). Partindo dessa lógica, os colonizadores submetiam os povos indígenas - de forma física, social e cultural - à subalternização, reduzindo-os a uma unidade étnico-racial inferior, com a finalidade de garantir as condições de manutenção e domínio das estruturas coloniais (Silva 2012).

Além da usurpação de seu território pelos colonizadores, a repressão da língua nativa imposta aos índios na administração pombalina provocou um encapsulamento perene do povo Kokama. Na reflexão dos autores Almeida \& Rubim (2012):

Os efeitos da interdição da língua indígena consistiram em fatores preponderantes para que a transmissão da lingua Kokama ficasse interrompida.[...] De maneira concomitante, sucedeu o que foi considerado o "desaparecimento" do povo Kokama. Um periodo obscuro na história deste povo, em que praticamente cessam as informações sobre ele. Os pais já não falavam a lingua, seus filhos viviam e conviviam com tios, tias, primos e primas, mas não se reconheciam como Kokama; casavam com pessoas de outros povos, sobretudo os Ticuna e passavam a se identificar como tais. Foi um prolongado tempo de negação e de existência atomizada, cujas manifestações culturais encontravam-se submetidas àquelas de outros povos, principalmente os Ticuna, cuja expressão demográfica e territorial os tornavam politicamente hegemônicos. (Almeida \& Rubim 2012: 69)

$\mathrm{Na}$ atualidade, os Kokama vivem dispersos em uma vasta região interligada por rios, igarapés, ilhas, floresta e cidades (na fronteira 
entre Brasil, Peru e Colômbia), exercendo a agricultura e a pesca como atividades principais de subsistência. No entanto, o fato de descenderem de famílias que vieram de regiões onde hoje se situa o território peruano é tomado como justificativa, por parte de certos setores do Estado brasileiro, para caracterizá-los como estrangeiros, na tentativa de negar-lhes direitos.

Historicamente marginalizados pelo Estado e divididos, em termos de nacionalidade, em brasileiros, peruanos e colombianos, o povo Kokama que vive do lado brasileiro da fronteira na região do alto Solimões, estado do Amazonas vem se mobilizado politicamente, tentando se beneficiar das políticas públicas estatais por meio de seu reconhecimento legal enquanto sujeitos detentores de direitos étnicos, e reivindicando, para isso, sua diferença enquanto coletividade distinta das demais (Vieira 2016).

Diferentemente dos nativos considerados “tribais", os Kokama são ignorados por serem considerados destribalizados, aculturados, integrados à cultura não indígena ou mesmo extintos enquanto grupo étnico. Mesmo mantendo suas tradições e seu modelo sociocultural, esses indigenas, por vezes, na tentativa de escapar de preconceitos, ocultam sua identidade étnica quando vinculados à sociedade nacional e à economia de mercado.

O processo de estigmatização desses indígenas em solo nacional está diretamente relacionado a suas origens peruanas, as quais se revelam, sobretudo, pela língua ou pelo sotaque espanhol exprimido por eles. Em um outro ponto, a autoclassificação étnica e a classificação pelos não indígenas, mediada pelo Estado nacional, são politizadas a ponto de dificultarem a aceitação e reconhecimento dos Kokama de origem peruana por parte das autoridades municipais brasileiras da tríplice fronteira, da Fundação Nacional do Índio (Funai), entre outras instituições governamentais.

Nessa região de fronteira, sobretudo em Atalaia do Norte, os Kokama são englobados como peruanos pela população local, o que significa submeter a identidade ética desses indígenas a um processo de nacionalização.

Vieira lembra que:

\begin{abstract}
O conceito de ser "peruano", no Peru fez sentido para os Kokama num contexto de valorização da construção do Estado Nação pelos governantes deste país vizinho, mas não no Brasil atual, pós Constituição Federal de 1988, que teoricamente enfatiza a diversidade étnica como valor. Aqui "Ser Kokama" tem valor não só simbólico, mas também instrumental [...].
\end{abstract} (Vieira 2016: 105)

Assim sendo, a questão da nacionalidade dos Kokama, vindos de além-fronteiras, impõe-se sobre a etnicidade como marcador de diferenças entre nós (os brasileiros) e eles (os peruanos).

No campo religioso, a totalidade adotou o cristianismo popular, em decorrência da evangelização de anos atrás (Rubin 2016). Pelas necessidades criadas pela ideologia dominante, em troca de proteção (do Estado, dos missionários ou de alguns patrões), de segurança econômica ou de manter seu território, renunciaram ao seu estilo de vida, a sua visão de mundo e a seus direitos (Vieira 2016).

Os Kokama estão em processo de retomar no cotidiano o uso de sua língua e seus rituais para reforçar os laços linguísticos nas aldeias e comunidades. No Brasil, especialmente na Amazônia, são poucos os falantes da língua kokama. Moseley (2010), em Atlas of the world's languages in danger, aponta que o kokama é uma das 190 línguas indígenas na lista de extinção.

Para o povo Kokama, a organização territorial baseia-se no critério de lugar (Rubin 2016), nos aparatos jurídicos e na relação com suas formas culturais. É assim que eles evocam o passado e acentuam sobremaneira a revitalização, por meio da educação diferenciada, a formação e a garantia de permanência dos professores indígenas que ministrem o ensino de língua e cultura nas escolas, o que corresponde à meta de fortalecimento da coesão social necessária a uma ação política e coletiva.

Nessa dinâmica de apropriação do espaço físico e simbólico, o fator educacional tornase um instrumento que assegura os direitos territoriais e dirime dúvidas, porventura existentes, sobre seu domínio. Portanto, a "construção da identidade indígena passa 
pela formação da Escola Indígena” (Almeida \& Rubim 2012: 75) e pela valorização das lideranças que falam a língua materna.

Nesse processo de luta por um modo de ser, pensar e viver de forma tradicional e luta por conquista de visibilidade étnica, surgem conflitos em virtude da competição por reconhecimento étnico e jurídico (em termos associativos) e alianças com setores da sociedade não indígena, com as demais etnias da região e dentro do próprio movimento social Kokama. Tais alianças buscam a garantia de direitos territoriais e intelectuais, bens culturais, patrimônio linguístico, educação e saúde diferenciadas, religiosidades, controle de recursos naturais, entre outras demandas e projetos com financiamento escassos (Vieira 2016).

A iniciativa da comunidade Kokama de criação do Museu Vivo Antonio Samias, com características singulares, enquadra-se em um perfil museológico que está muito mais voltado para pensar e reafirmar suas memórias e história, conquistar reconhecimento enquanto indígena Kokama perante os não índios e outras etnias indigenas - diante das organizações indígenas e indigenistas - do que simplesmente expor coleções de objetos. É, portanto, uma ação cujo propósito visa produzir, pelos artefatos selecionados e apresentados, um documento de identidade.

Para interpretar a iniciativa de criação desse museu vivo, é necessário perceber as estratégias de adaptação e ressignificação dos elementos da cultura Kokama. Em Barth (2000), a mudança de comportamento, a interação e a adoção de alguns dos elementos da cultura envolvente não significa que os Kokama estejam se misturando, perdendo a identidade ou deixando de perceber ou de ser eles mesmos, visto que a existência cultural de um grupo étnico também se faz por movimentos de ajustes das suas estratégias de luta.

Conforme destaca Oliveira Filho (2004), esse discurso teórico e interpretativo - que atribui ao índio os termos "misturado", "remanescente" ou "descendente" - possui um viés ideológico que desqualifica e nega a capacidade adaptativa e diferenciada dos indigenas de atender as demandas da cultura e os impõe a representação idealizada de índios puros, do passado, apresentados como antepassados míticos.

O autor elaborou seus estudos tomando como sujeitos de sua análise os índios do Nordeste, destituídos de seus territórios, em decorrência da ação dos colonizadores e devido à ocupação de suas terras por fazendeiros e agricultores não indígenas. A reflexão de Oliveira Filho foi deslocada para esta pesquisa no intuito de fornecer subsídios teóricos para se pensar a atribuição, por parte autoridades e pela população regional, de "índios misturados" (Rubin 2016) aos Kokama da cidade de Manaus. Superar o discurso da mistura é necessário para que essa e outras comunidades indígenas brasileiras sejam vistas como coletividades organizadas, que formulam uma identidade própria, instituem mecanismos de tomada de decisão e de representação e são capazes de reestruturar as suas formas culturais com o meio ambiente e com o universo religioso (Oliveira Filho 2004).

É possível também entender a criação do Museu Vivo como elemento fundamental de constituição de uma comunidade de argumentação na qual o povo Kokama, com sua cultura heterogênea e diversificada, articulase por meio de ações - considerando que os conteúdos simbólicos não correspondem unicamente a uma projeção de modelos atemporais e inconscientes, mas representam uma tentativa de solução de problemas surgidos no curso das interações sociais.

Cabe dizer que a nomeação explícita dos sujeitos e/ou agentes sociais na criação desses museus vivos corresponde à busca por possibilidades concretas de autodeterminação cultural, outrora ocultada, invisibilizada e designada de forma genérica. Indissociáveis da consciência e do processo de autodeterminação dos agentes sociais, os "museus vivos" correspondem às identidades coletivas mencionadas.

A invisibilidade dos Kokama, para Almeida e Rubin (2012), também se deve à proximidade física e relações de parentesco estabelecidas via casamento com os Tikuna, que já se encontravam articulados politicamente e com suas organizações político-representativas 
estruturadas. Em decorrência disso, durante toda a década de 1980 e 1990, durante as demandas por identificação de terra indígena, a Funai interpretou os Kokama como sendo Tikuna; e onde havia a presença de Kokama, estes eram ignorados como grupo étnico diferenciado.

Pensada como uma forma de atualização da luta por direitos identitários e territoriais, o processo de organização do Museu Vivo impõe um esforço de repensar esse espaço como uma ferramenta analítica do presente, que recoloca artefatos da vida cotidiana, símbolos religiosos, narrativas míticas, instrumentos de caça, coleta, pesca e de cultivo agrícola, entre outros objetos rotineiros capazes de representar de maneira material e simbólica a etnia Kokama.

Para Almeida (2017), erigir museus vivos, inserindo neles somente o que o próprio povo ou comunidade considera relevante como elemento representativo de sua memória cultural, demarca uma posição de interlocução com os discursos estigmatizantes que classificaram os povos indígenas na perspectiva de um modo subalterno de existência material e subjetiva. Rodeada de preconceito, semelhante a outras comunidades tradicionais, a comunidade Kokama tem sido submetida a uma narrativa de distinção, que produz sua não existência.

Em Santos (2002), a luta pela autodefinição torna possível agir de maneira a superar as ausências instituídas aos Kokama. A propositura de criação do Museu Vivo corresponde a uma estratégia de luta política cuja ação visa destacar os saberes, que dão credibilidade a práticas sociais e representações do conhecimento aproximado e não real. Esse procedimento permite conceber e compreender a realidade a partir da estratégia de comunicabilidade dos saberes do povo Kokama apresentados no Museu Vivo, ou seja, idealizado pelo próprio povo.

Considerando a diversidade de experiências de criação do Museu Vivo, os Kokama da comunidade Nova Esperança atuam na construção e composição de suas coleções, dando relevância às pautas reivindicatórias que passam a dar lugar ao simbólico, ao imaterial, aos conhecimentos tradicionais que lhes são inerentes (Dourado 2017) e à existência de uma pluralidade de formas de conhecimento além do conhecimento científico.

Associado ao processo de mobilização política, a proposta de criação de lugares sociais para afirmar a memória de luta (designados pelos agentes sociais e organizadores), como museus vivos ou pequenos museus, expressa, de forma independente das ações do Estado, as reivindicações pelos direitos territoriais, a convergência entre o econômico e o simbólico e a luta pelo reconhecimento identitário.

Segundo Castells (1999: 23), do ponto de vista sociológico, "toda e qualquer identidade é construída", logo, essa busca pelo reconhecimento identitário requer a análise da relação entre as narrativas/discursos de acolhimento do denominado indígena na teia social e as formas de governo/controle exercido sobre esses povos.

Para essa reflexão, a ideia de hospitalidade ${ }^{3}$ condicional age no enquadramento do outro, negando-lhe a reinvenção; e a incondicional acolhe o outro, sem exigir-lhe mudança ou transformação. O pensamento pautado na ideia de desconstrução em Derrida \& Roudinesco (2004) permite pensar o processo de diferenciação para além dos limites culturais, nacionais, linguísticos, humanos, e ajuda a pensar a construção da subjetividade do outro, desconsiderando qualquer exigência de encaixamento de suas potencialidades (Aguiar 2012).

Com base no princípio da hospitalidade incondicional derridiana, o ato de buscar a reinvenção da identidade pelos Kokama corresponde à desconstrução, que propõe a abertura e reinvenção do pensamento, seja na forma de dispositivo jurídico, político, social ou cultural. Isso implica acolher o modo de ser, pensar e viver da etnia Kokama, reconhecendo sua autonomia, sem enquadrá-la na ideia de cultura pura.

Assim, ao proporcionar a construção da autonomia, a sustentabilidade passa a incluir a apropriação do conhecimento como

3 A ideia de hospitalidade em Derrida está relacionada ao ato de acolher e oferecer abrigo ao outro, garantindo a différance na produção de sua existência, de modo que não aconteça o apagamento de um sujeito diante do outro (Aguiar 2012). 
complexidade, haja vista que os problemas de dinâmica social, enquanto espaço socialmente construídos, são fenômenos complexos (Leff 2015). Esse é um dos motivos pelo qual o termo "sustentabilidade" precisa articular as diversas ações e comportamentos humanos, com a esfera ambiental, social, cultural e política.

A proposta dos museus vivos surge da demanda, mobilização e estratégia de luta pela garantia de existência humana, material e cultural dessa etnia. Podemos defender a tese de que a função social desses museus emerge com a intencionalidade de tratar as discussões sobre sustentabilidade cultural, relacionando-a à vivência de reafirmação da identidade indígena Kokama.

\section{Sustentabilidade sociocultural}

O princípio de sustentabilidade adotado nesta pesquisa visa "desconstruir a ordem antiecológica herdada da racionalidade econômica [...] para caminhar para uma [...] ordem social, orientada pelos princípios de sustentabilidade ecológica, democracia participativa e racionalidade ambiental" (Leff 2015: 28). A saber, é na organização coletiva que os Kokama encontram a possibilidade de participar e, assim, reivindicar o cumprimento das ações de políticas públicas e garantir sua sobrevivência.

No cenário da política ambiental urbana, considera-se que as expectativas indígenas pela garantia de seus direitos de cidadãos estão ancoradas na dimensão social e na reafirmação de sua identidade, o que denominamos sustentabilidade sociocultural, que corresponde à luta pela sua existência identitária no contexto urbano.

A proposta de abordar a sustentabilidade na dimensão sociocultural justifica-se por ela discutir as mobilizações indígenas que acenam para a participação das associações indígenas na criação de museus e na elaboração de processos democráticos, de políticas públicas no âmbito da Assistência Social, da Saúde e da Educação, conforme determina a Constituição de 1988 (Brasil 1988).
Em seu conjunto, essas estratégias que implicam decisões e ações do governo e de outros atores na resolução de problemas sociais são definidas como políticas públicas; após a sua devida implementação, é necessário saber se a parte interessada foi atendida. A política pública baseada na participação das organizações indígenas, na gestão de seu patrimônio e na garantia de atendimento a suas necessidades básicas, já constitui uma das características da sustentabilidade sociocultural.

Com base nessa compreensão, a política pública se configura como uma ferramenta ou mecanismo de equidade e instrumento dinâmico na promoção de mudança social, direcionada para a garantia do bem-estar de segmentos sociais historicamente destituídos. No caso deste estudo, a autodeterminação cultural e a luta pela assistência material - que repercutem nas condições de vida - impulsionaram a etnia Kokama da comunidade Nova Esperança a buscar no associativismo um instrumento coletivo consistente para obter visibilidade e conquistas socioculturais (Vieira 2016).

Os princípios norteadores para o desenvolvimento comunitário baseiam-se na cooperação, nos laços familiares entre gerações com ligações ancestrais e em um projeto de revitalização da cultura, que demonstra a autenticidade de sua própria ética ambiental, bem como a preocupação com a garantia de bem-estar das gerações futuras e o respeito pelo ecossistema.

Conforme Souza (2016), a perspectiva da natureza a partir da compreensão das sociedades indígenas advém do respeito mútuo estabelecido nas diversas relações sociais entre povos e demais seres. Essa forma de entendimento da existência humana apresentase como fundamental em reflexões sobre sustentabilidade, visto que interliga os saberes indígenas e suas relações com o meio ambiente em um prisma de interdependência.

Nas últimas décadas, a luta de autodeterminação cultural para os Kokama passou a ter uma finalidade política fundamentada no processo da construção de sua identidade étnica enquanto coletividade e no reconhecimento territorial (Vieira 2016). 
Nas últimas décadas do século XX, conforme aponta Vieira (2016), os Kokama reaparecem no Alto Solimões, reivindicando seus direitos a partir da criação de suas associações. O Artigo 232 da Constituição "reconhece as organizações indígenas como uma das partes legítimas para ingressar em defesa de seus direitos e interesses" (Brasil 2012: 130). Mediante esse dispositivo legal são estabelecidos os diálogos entre as comunidades indígenas e o Estado por meio de seus representantes legais.

$\mathrm{Na}$ atualidade, a comunidade Kokama Nova Esperança - localizada no ramal do Brasileirinho, em Manaus (AM) -, tem fortalecido sua força política por meio da AKIM, criada em 2010.Em 20 de junho de 2012, após alguns conflitos, o grupo saiu da terra particular e migrou para uma terra no mesmo ramal, doada por Júlio, que decidiu fazer a doação para que o povo tivesse suas reivindicações aceitas, e os benefícios chegassem a todos. Assim a comunidade recomeçou a caminhada (Rubin 2016).

O fenômeno associativo desenvolvido entre os Kokama, sobretudo após a Constituição Federal de 1988, tem garantido a reivindicação dos direitos indígenas. As então criadas associações indígenas conectam demandas locais a circuitos políticos regionais, estaduais, nacionais e transnacionais na tentativa de captação de recursos e parcerias, ao mesmo tempo que propiciam visibilidade às lutas dos povos indígenas.

A associação dos Kokama, principalmente para criar o Museu Vivo, representa a luta para reescrever a tradição do povo em um campo de produção da etnicidade marcado por estratégias de politização da cultura e formação de alianças interétnicas mais amplas.

Segundo Vieira (2016):

Nas últimas décadas os Kokama, por meio de suas associações, estão tentando participar de projetos (contando com a colaboração de assessores de ONGs, órgãos governamentais municipais, estaduais e federais, universidades e antropólogos, etc.) para obter fontes alternativas de renda para as comunidades. Tais empreendimentos visam fundamentalmente o fortalecimento da identidade étnica, valorização das tradições, o desenvolvimento sustentável, a inserção nas políticas indigenistas nas áreas de saúde, educação e alternativas econômicas, bem como o reconhecimento étnico e territorial. (Vieira 2016: 70)

\section{Inclusive, o associativismo da AKIM} tem tornado efetiva sua participação nas ações governamentais e nas políticas públicas definidas para os povos indígenas. Dentre as ações e políticas, destaca-se a inclusão específica da categoria indígena no documento oficial da Política Nacional de Assistência Social (PNAS), que visa tornar "visíveis aqueles setores da sociedade brasileira tradicionalmente tidos como invisíveis ou excluídos das estatísticas população em situação de rua, adolescentes em conflito com a lei, indígenas [...]" (Brasil 2005).

As políticas do Ministério do Desenvolvimento Social e Combate à Fome (MDS) voltadas aos povos indígenas têm favorecido o acesso ao Programa Bolsa Família, que age no âmbito da segurança alimentar e nutricional, combatendo a fome e a desnutrição. Contudo, essas políticas específicas foram desencadeadas pelas reivindicações dos movimentos sociais e contam com a participação dos grupos atendidos e do Estado.

O MDS, em parceria com o Ministério do Meio Ambiente, desenvolve a ação Carteira Indígena, que apoia projetos - executados por comunidades indígenas - referentes à produção sustentável de alimentos, beneficiamento e comercialização da produção agrícola, artesanal e agroextrativista, bem como a revitalização de práticas e saberes tradicionais.

Por meio da Lei no 9.836, de 23 de setembro de 1999, criou-se o programa Subsistema de Atenção à Saúde Indígena, vinculado ao Sistema Único de Saúde (SUS) (Brasil 2004), responsável por fornecer atendimento básico à população indígena. $\mathrm{Na}$ entrevista realizada com as famílias que recebem esse atendimento, Costa (2015) conclui que o atendimento à saúde indígena ainda se encontra insatisfatório.

Com a extinção da política de atenção à saúde do indígena, em janeiro de 2013, pela Secretaria Municipal de Saúde, a promoção 
da saúde indígena tornou-se responsabilidade do Núcleo de Saúde do Homem e Grupos Especiais, que abarcam a saúde indígena, saúde da população negra e saúde no sistema penitenciário (Costa 2015).

No que tange à educação diferenciada, essa modalidade educacional caracteriza-se como política pública específica para os indígenas, e que é garantida por diversos dispositivos legais que asseguram a utilização de suas línguas maternas e processos próprios de aprendizagem, conforme determina a Constituição Federal (Art. 210, § 2²). A Lei no 9.394, de 1996 - Lei de Diretrizes e Bases da Educação Nacional (LDBEN) -, por sua vez, garante aos povos indígenas a oferta de educação escolar intercultural e bilíngue.

Em sua pesquisa de campo junto com a referida comunidade Kokama, Costa (2015), relata que, segundo a liderança do grupo, o atendimento educacional diferenciado é uma ação fruto da reivindicação da comunidade, e cujos resultados, que visam o fortalecimento da identidade indígena dos Kokama nascidos em Manaus, já estão sendo apresentados, podendo ser visualizados no uso de palavras do vocabulário da língua Kokama, tais como nomes de animais, frutas, partes do corpo, elementos da fauna e flora e da culinária.

É com base na dinâmica de resistência que o povo Kokama, durante séculos, tem buscado redesenhar novas fronteiras políticas, de forma a persistir na afirmação de sua identidade étnica, mediante a mobilização para a conquista do Registro Administrativo de Nascimento do Índio (Rani), documento que ratifica a identidade étnica do indígena requerente. As reivindicações para a obtenção do Rani são diversas e ocorrem, do Baixo Rio Negro ao Alto Solimões, de diferentes formas (Almeida \& Rubin 2012).

Ainda no campo de suas conquistas, além da saúde e educação, os índios Kokama estabeleceram parceria com o Projeto da Nova Cartografia Social da Amazônia (PNCSA), entidade de pesquisa que tem orientado a liderança indígena Kokama na criação dos museus vivos em seus territórios. A ideia foi levada à comunidade pela professora Altacy Rubim, Kokama, linguista e gerente da educação indígena da Secretaria Municipal de Educação (SEMED).

O objetivo de criação dos museus vivos é buscar a afirmação da identidade, saberes e fazeres representativos desse povo e comunidade tradicional ${ }^{4}$. Nesses respectivos museus o caráter de resistência e a elaboração de projetos socioculturais são mobilizados para se contraporem à lógica de organização dos museus ocidentais. Sendo assim, a classificação e exposição dos artefatos e instrumentos de trabalho, musicais e religiosos compõem o acervo de elementos coextensivos aos "seus modos de criar, fazer e viver" (Almeida 2017).

A composição das coleções é realizada por integrantes de unidades sociais designadas como "comunidades tradicionais". A participação de agentes sociais e integrantes do projeto ocorre em constante articulação com os pesquisadores acadêmicos sob a orientação do professor Alfredo Wagner Berno de Almeida, do PNCSA; da museóloga Heloisa Bertol Domingues, do Museu de Astronomia e Ciências Afins (Mast); e de Cynthia Carvalho Martins, do Programa de pós-graduação em Cartografia Social e Política da Amazônia, da Universidade Estadual do Maranhão.

A concepção de museus vivos adotada pelo PNCSA diverge da ideia de "museus comunitários" por considerar que essa expressão, adotada oficialmente pelas políticas governamentais, utiliza a ideia de coletivo como uma designação genérica (Almeida 2017). Desse modo, em lugar de apresentar uma monocultura cientificista enquadrada em uma vitrine, os museus vivos dão ênfase à construção da memória de diferentes grupos sociais e identidades que organizam seus próprios acervos museais.

Considerando a dimensão social e cultural da sustentabilidade, os museus vivos agregam práticas de valorização e protagonismo de comunidades tradicionais em torno da ampliação da natureza e significado do acervo

4 O significado da expressão "povos e comunidades tradicionais" remete não a uma continuidade ou a uma transmissão de saberes de uma geração a outra ou ainda a um tempo linear, mas a rupturas, invenções e emergência de identidades coletivas no tempo presente. 
por meio de territórios inteiros, artefatos visíveis aos olhos do observador - como bandeiras, pinturas, artesanato e danças -, bem como outras percepções e apreciações - como músicas e outros sinais diacríticos, língua, genealogia, mitos e história da localidade de origem que podem ser conferidos por meio da história narrada pelos próprios Kokama (Rubim 2017).

\section{O cenário do Museu Vivo e as conquistas do povo Kokama}

Em Manaus, são dois os "museus vivos" Kokama, localizados em área urbana ${ }^{5}$ o Museu Vivo Lua Verde ${ }^{6}$, integrado ao Espaço Cultural Indígena Kokama Yatsi Ikira, e o Museu Vivo Antonio Samias, integrado ao Centro de Ciências e Saberes da comunidade Nova Esperança. Esses museus, mediante a parceria entre as comunidades Kokama e o PNCSA, foram os primeiros a serem implementados, ganhando força por transformarem os indígenas em protagonistas da sistematização e organização de seus respectivos saberes tradicionais. Neste artigo, apresentamos apenas o Museu Vivo Antonio Samias.

Inaugurado no dia 17 de Junho de 2017, o Centro de Ciências e Saberes Tradicional Kokama Antonio Samias, localizado na Estrada do Brasileirinho, corresponde a uma iniciativa do projeto "Centro de Ciências e Saberes: experiências de criação de 'museus vivos' na afirmação de saberes e fazeres representativos dos povos e comunidades tradicionais”.

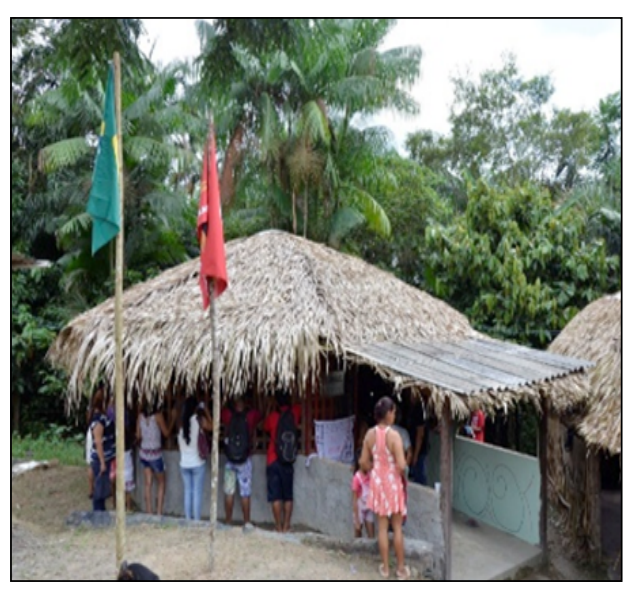

Fig. 1. Museu Vivo Antonio Samias.

Fonte: Arenillas (2017).

O nome Antonio Samias atribuído ao museu é uma homenagem a um dos patriarcas do movimento Kokama (o primeiro da Figura 2, que mostra imagens de patriarcas), imbuído na história de luta e conquista para que a língua Kokama viesse a ser ensinada nas escolas. Depois de Antonio Samias o patriarcado foi assumido por Francisco Samias que, ao falecer, foi repassado ao seu filho Edney Samias (Rubim 2016).

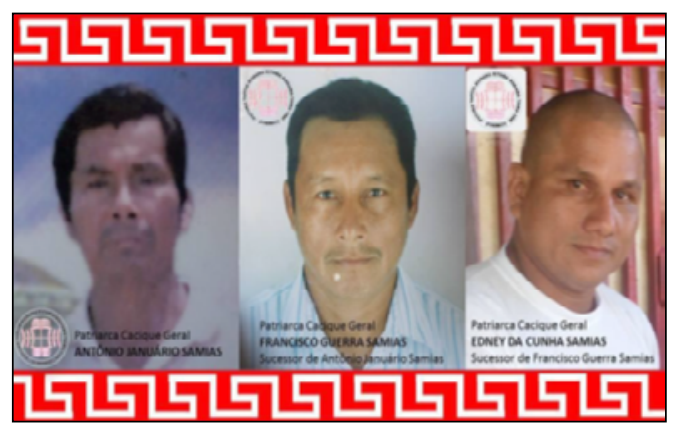

Fig. 2. Patriarcas Kokama.

Fonte: Rubim (2016).

Além da apresentação de músicas Kokama e da cerimônia de distribuição de diploma de reconhecimento aos caciques presentes, o atual patriarca nacional do povo Kokama, Edney da Cunha Samias, pronunciou-se, manifestando seu contentamento: 
Para a gente valorizar nossa lingua Kokama, porque ela não está morta, está mais que viva e a inauguração do museu Kokama é o primeiro de muitos que virão, nós respeitamos a natureza, nós somos a natureza, nós não somos maior que a natureza, nós não somos mais que natureza, quando o Kokama invade uma terra, o indio invade uma terra para dar vida pela terra que tá adormecida ou sem vida, não é à toa, é a necessidade de valorizar, Kokama é vida. (Arenillas 2017)

No que tange a sua especificidade, o respectivo museu Kokama é uma experiência que está profundamente ligada às mobilizações políticas desse povo. A dinâmica desse espaço não o resume a lócus para institucionalização da memória ou para uma apologia da "versão indígena" do museu.

A perspectiva ideológica dos museus vivos pensados pelo PNCSA (Almeida 2017) distanciase dos museus ocidentais e até mesmo dos ecomuseus - ancorados na vertente da Museologia Social - por evitar as implicações burocráticas das medidas cadastrais características das políticas museais, que prescinde da submissão à rigidez e uniformidade dos regulamentos e homogeneidade das normas oficiais.

Nesse sentido, por não corresponder às iniciativas passiveis de serem inseridas no Cadastro Nacional de Museus, criado e implementado pelo Instituto Brasileiro de Museus (Ibram), o Museu Vivo Antonio Samias é gerido, pensado e desenvolvido por integrantes da própria comunidade por meio de iniciativas diversas e autossustentáveis, "[...] mantidas por fundos de reserva de unidades familiares que se empenharam em sua criação e garantem a sua rotina cotidiana" (Almeida 2017: 57).

Elaborado com preocupação didática com fins de ministrar conhecimentos, o catálogo do Centro de Ciências e Saberes Tradicionais Kokama Antônio Samias apresenta, a partir dos objetos expostos, a memória social do povo Kokama e de seus líderes. As armadilhas em miniatura apresentadas a seguir tentam aproximar os jovens que vivem na cidade das condições de vida marcadas pelo uso cotidiano dos recursos naturais, notadamente a fauna das aldeias.

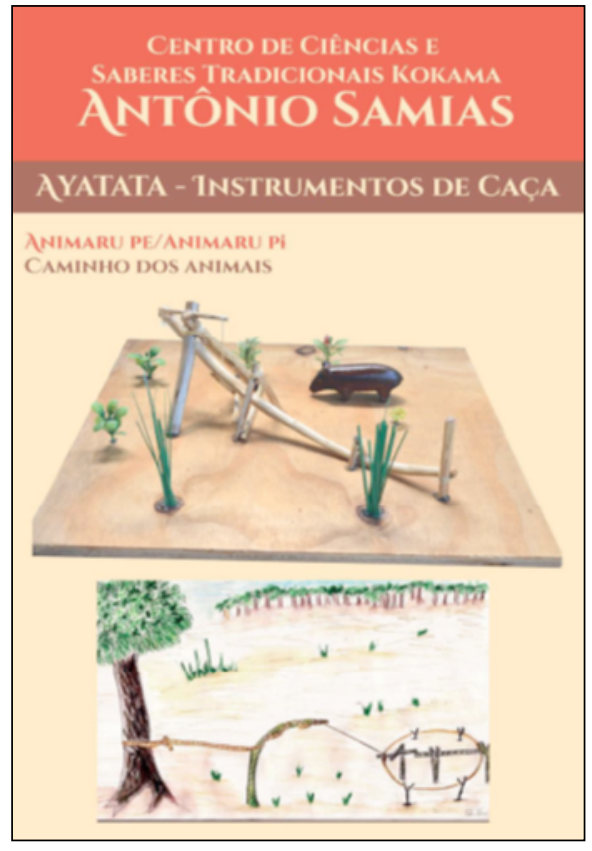

Fig. 3. Catálogo de exposição permanente do Museu Vivo Antonio Samias que apresenta miniaturas de instrumentos de caça.

Fonte: Almeida (2017: 271).

Segundo Dourado (2017), a busca por reconhecimento não está pautada na proteção ao patrimônio cultural e ingresso dos bens culturais em uma lista, conforme consta oficializado na legislação. De modo contrário, nos museus vivos a produção e transmissão dos saberes compõem a principal motivação para a realização de exposições. Esses lugares sociais de troca, de educação, de manutenção de ritos, de mitos e de aprendizado das línguas é a própria materialização da identidade do povo Kokama.

Os agentes sociais tornam-se protagonistas de uma nova forma de sistematizar suas histórias, suas memórias, seus saberes. Essa experiência dos Centros de Ciências e Saberes não depende do Estado, pois corresponde a uma modalidade de resistir a ele e a sua política museal. Trata-se "[...] de uma expressão artística elaborada do ponto de vista do povo Kokama" (Rubim 2017: 147).

Os Kokama utilizam-se do museu como forma de representação da vida à revelia das 
imposições do que foi planejado e imposto pelo Estado como critério para avaliá-los, acolhê-los ou negar-lhes o acolhimento (Derridá 2004; Aguiar 2012). Opondo-se ao controle/governo do Estado sobre seus museus, os Kokama assumem uma experiência de existência em oposição ao modelo e norma que lhes é apresentado como critérios de enquadramento de sua cultura.

A criação dos museus vivos corresponde a um conhecimento emancipatório como forma de resistência ao princípio colonizador de racionalidade cognitivo-instrumental de ciência imposto pelo modelo de museu regulado pelo Estado.

O ser indígena se situa dentro do discurso
da sustentabilidade, da globalização, da
democracia, da capitalização da natureza e da
cultura; posicionando-se perante as estratégias
de controle [...] para reafirmar suas identidades,
seus direitos, reclamando autonomia como o
direito de ser, o direito à identidade, o direito ao
território. (Leff 2003: 53)

A organização do museu vivo Kokama mostra a capacidade do indígena, amparado pela participação consciente que se fortalece no coletivo das organizações, de perceber a realidade em que está inserido e buscar alternativas para enfrentar as relações de poder que se expressam no complexo processo de construção sociocultural de suas vivências. Essa mobilização é identificada na busca pela reafirmação e visibilidade para a identidade indígena e por seus direitos de participação no exercício da cidadania.

As fichas de identificação dos artefatos em exposição permanente no Museu Vivo Antonio Samias foram elaboradas na própria língua Kokama, não havendo versão na língua portuguesa. Um "guia” Kokama é o responsável por explicar, em português, as memórias reavivadas nas miniaturas das armadilhas das diferentes formas de caçar, pescar, fazer cerâmica e artesanato.

Os Kokama reivindicam o respeito a suas diferenças, o direito de serem indígenas, e se interessam pela participação no processo de desenvolvimento como modo de obter acesso aos serviços necessários a sua existência, desde que esse processo seja planejado de forma dialógica, democrática e mais simétrica, sobretudo com a participação desses sujeitos.

Essa dimensão da cidadania inclui o aprendizado e a convivência entre a sociedade e os indígenas, na condição de cidadãos emergentes, que se recusam a permanecer nos lugares que foram definidos a eles social e culturalmente. A reinvenção dos modos de vida indígena, avessos ao modelo estatal, revelam o potencial para se expressarem em vozes e línguas diferentes, rompendo com a sonoridade da harmonia e da uniformidade expressiva.

As histórias antigas dos Kokama são rememoradas nesse ambiente por meio das dramatizações das histórias antigas, da contação de histórias, das aulas da língua Kokama, dos ensaios das músicas e danças tradicionais e da produção de materiais didáticos, entre outros. O grande desafio é encontrar formas de propiciar a continuidade da produção e da reprodução desses saberes, não apenas para que não se extingam, mas para que não percam os significados para os sujeitos que os possuem diante dessa aproximação com o mercado.

\section{Considerações}

Esta pesquisa realizada acerca da realidade de lutas, resistências e conquistas dos índios Kokama na cidade de Manaus permitiu discutir, dentre outras questões, a participação ativa de líderes Kokama na política indígena de resistência à invisibilidade imposta a eles, e que culminou na criação de diversas associações locais nas últimas duas décadas. A participação das organizações indígenas na gestão de seu patrimônio e na garantia de atendimento a suas necessidades básicas de existência material e cultural representa uma nova configuração de articulações políticas que ainda está em construção, mas que poderá definir melhor as reivindicações desse grupo étnico. Esta pesquisa revelou que essa comunidade optou por se autodeterminar e autoconstruir culturalmente, apropriando-se de espaços e ideias - a exemplo da criação 
do Museu Vivo - como forma de resistência ao princípio colonizador de racionalidade cognitivo-instrumental cientificista do modelo de museu-vitrine regulado pelo Estado, o que representa mais uma possibilidade de produção de sua visibilidade e, consequentemente, fortalecimento da luta pela sua identidade étnica.

Trindade, D.S.A; Cordeiro, D.G. The Living Museum Antonio Samias and the social sustainability of the indigenous Kokama. R. Museu Arq. Etn., 30: 104-117, 2018.

\begin{abstract}
The foundation of the Association of the Indigenous Kokama from the city of Manaus (AKIM) has amplified the possibilities of reinforcement of their identity and of reaching public policies, settled for the Indigenous peoples subjected to a process of social invisibility since the occupation of the Amazon by the colonizers. This qualitative research, of bibliographic aspect, aims to analyze the community articulation of the Indigenous Kokama by the creation of the Living Museum Antonio Samias, as a form of reaffirmation of their ethnic identity and sociocultural sustainability. In this way, it was noticed that, by articulating themselves in a sociopolitical community/organization, through struggles for cultural redetermination, the Indigenous settled a partnership with the Nova Cartografia Social Program in Amazon (PNCSA), to reinforce the social practices of their people and their leaders as a mechanism of preservation of memory and resistance.
\end{abstract}

Keywords: Indigenous identity; Sociocultural sustainability; Living Museum Antonio Samias; Ecomuseums; Cultural diversity.

\title{
Referências bibliográficas
}

Aguiar, J.V.S. 2012. Narrativas sobre os povos indígenas na Amazônia. Edua, Manaus.

Almeida, A.W.B. 2017. A historicidade da vida contra a museificação: os museus e os mapas nos "centros de ciências e saberes. In: Almeida, A.W.B.; Oliveira, M.A. (Orgs.). Museus indígenas e quilombolas: centro de ciências e saberes. UEA Edições; PNCSA, Manaus, 47-83.

Almeida, A.W.B.; Rubim, A.C. 2012. Kokama: a reconquista da língua e as novas fronteiras políticas. Revista Brasileira de Linguística Antropológica 4(1): 67-80.

Arenillas, M. 2017. Inauguração do Centro de Ciências e Saberes Tradicionais Kokama Antônio Samias na comunidade indígena kokama do ramal do Brasileirinho, na cidade de Manaus-AM.
Disponível em: $<$ https://bit.ly/2SYkTNn $>$. Acesso em: 01/04/2018.

Barth, F. 2000. Os grupos étnicos e suas fronteiras. In: Lask, T. (Org.). O guru, o iniciador e outras variações antropológicas. Contra Capa, Rio de Janeiro, 7-67.

Brasil. Constituição. 1988. Constituição da República Federativa do Brasil. Senado, Brasília.

Brasil. Ministério do Desenvolvimento Social e Combate à Fome. 2004. Relatório GT Povos Indígenas. MDS, Brasília.

Brasil. Ministério de Desenvolvimento Social e Combate à Fome. 2005. Pesquisa nacional de assistência social PNAS/2004. MDS, Brasília. 
Castells, M. 1999. O poder da identidade. Paz e Terra, São Paulo.

Costa, R.G.C. 2015. Direito dos povos indígenas e sustentabilidade: desafios de ser/sobreviver como Cocama longe da terra indígena. In: Anais da VII Jornada Internacional de Políticas Públicas, 2015, São Luiz.

Derrida, J; Roudinesco, E. 2004. De que amanhã... diálogo. Zahar, Rio de Janeiro.

Dourado, S.B. 2017. O patrimônio cultural para além da patrimonialização. In: Almeida, A.W.B.; Oliveira, M.A. (Orgs.). Museus indígenas e quilombolas: centro de ciências e saberes. UEA Edições; PNCSA, Manaus, 172-183.

Freitas, M.A.B. 2002. O povo Kokama: um caso de reafirmação de identidade étnica. Dissertação de mestrado. Universidade Federal do Amazonas, Manaus.

Leff, E. 2003. Aventuras da Epistemologia Ambiental: da articulação das ciências ao diálogo de saberes. Garamond, Rio de Janeiro.

Leff, E. 2015. Saber ambiental: sustentabilidade, racionalidade, complexidade, poder. Vozes, Petrópolis.

Oliveira Filho, J.P. 2004. Uma etnografia dos índios misturados: situação colonial, territorialização e fluxos culturais. In: Oliveira, J.P. (Org.). A viagem da volta: etnicidade política e reelaboração cultural no nordeste indígena. Contra Capa, Rio de Janeiro.

Rubin, A.C. 2016. O reordenamento político e cultural do povo Kokama: a reconquista da língua e do território além das fronteiras entre o Brasil e Peru. Tese de doutorado. Universidade de Brasília, Brasília.

Rubin, A.C. 2017. Os “museus vivos" Kokama em Manaus-AM. In: Almeida, A.W.B.; Oliveira, M.A. (Orgs.). Museus indígenas e quilombolas: centro de ciências e saberes. UEA Edições; PNCSA, Manaus, 147-157.

Santos, B.S. 2002. Para um novo senso comum: a ciência, o direito e a política na transição paradigmática. Cortez, São Paulo.

Said, E.W. 1990. Orientalismo: o Oriente como invenção do Ocidente. Companhia das Letras, São Paulo.

Silva, M.C. 2012. O país do Amazonas. Editora Valer, Manaus.

Souza, A.H.C. 2016. Sustentabilidade sociocultural de indígenas em área urbana. Tese de doutorado. Universidade do Vale do Itaquari, Lajeado.

Vieira, J.M.T. 2016. A luta pelo reconhecimento étnico dos kokama na tríplice fronteira Brasil/Colômbia/ Peru. Tese de doutorado. Universidade Estadual de Campinas, Campinas. 